\title{
Challenges in Teaching Language and Literature: An EFL Perspective
}

\author{
Bh.V.N. Lakshmi \\ Professor of English, Shri Vishnu Engg. College for Women, JNTUK, Bhimavaram, India
}

\begin{abstract}
Language and Literature are not just a part of human expression but also of life, culture and history. No wonder then the teaching methods proposed by academic scientists are only catalysts that can supplement teaching-learning process, which is independent to a teacher and is subjected to change based on place and time. Orthodox religion and liberal language are always paradoxical to each other however the ubiquity of English language is changing the perspective of even conservative countries. There are the linguistic, cultural, educational, political and personal challenges that Arabic students face while learning English language. This paper is my sincere attempt to incubate my teaching-learning experience and to provide a preparatory glance for those who wish to see their career prosperity in the Arab world.
\end{abstract}

Key words: language, challenge, experience, innovation, EFL, Arabic Students

\section{Introduction}

Language and Literature are not just a part of human expression but also of life, culture and history. No wonder then the teaching methods proposed by academic scientists are only catalysts that can supplement teaching-learning process, which is independent to a teacher and is subjected to change based on place and time. A lot of research is done on methods of teaching language and literature and many programs cropped up to train teachers both native and non-native speakers. Programs such as TESOL, TESL, ESL, CELTA, DELTA etc., are now mandatory to ESL teachers to teach abroad. Though these programs differ from one another in certain aspects, their objective is same. Upgrading traditional methods with current technology and designing innovative practices that can cater to diverse academic standards of students is their common motto. Outcome based approach is the need of the hour, since world is moving towards globalization.

\section{My Experience of Teaching Language and Literature}

Orthodox religion and liberal language are always paradoxical to each other however the ubiquity of English language is changing the perspective of even conservative countries. Two years of passionate involvement in teaching-learning process in the most traditional Arab country gave enough impetus to verbalize my experience. As a non-native EFL teacher it is not a less challenge yet it gave a scope for implementation of innovative aspects in teaching-learning process. English language being introduced in the school curriculum not at primary level and medium of instruction being Arabic, English language is still a foreign tongue to most of them. They peculiarly practice to memorize letters instead of words in English. For them English Language is a mere subject and not yet a communicative tool in their everyday life. Writing in English is another challenge to Arab students. There is a lot of difference between Arabic writing and English writing in terms of style and organization. For instance they write Arabic from left to right. However, most of girl students still opt for English Language and Literature course at undergraduate level. Teaching is the most preferred profession for girls to other jobs.

\subsection{Challenges in teaching EFL to Arab students}

\section{Review of related literature}

In the Department of English, usually faculty with Arabic mother tongue out number non-Arabic teachers. This may not be a major limitation in Universities established in urban areas but certainly in rural areas the factor plays a key role in teaching-learning process. Most of the Arab English teachers' medium of instruction is Arabic. It is not totally an impediment since in 'self access' method students tend to learn the target language using their mother tongue. But in rural areas this method is affecting students' English language acquisition skills. Result is that most of the girl students in the Department of English come out with considerably good grades but majority of them cannot communicate in English either in spoken or written form. Since my experience is limited to a rural area, all of my observations may not be applicable to institutions established in urban areas. English course syllabus at undergraduate level is on par with Western standards. Certainly there is a mismatch between the standard of syllabus and the standards of students. This situation enforces bigger challenges on the part of the teacher, demanding greater patience and perseverance. 


\subsection{Limitations in Arab students' learning EFL}

There are the linguistic, cultural, educational, political and personal challenges that Arabic students face while learning English language. Students face problems in pronouncing certain sounds in English. They say 'bark' for 'park' and the reason as mentioned by Dr Intakhab Alam Khan in one of his research papers is that $/ \mathrm{p} /$ sound is missing in Arabic[1]. Another peculiarity is that they read the word 'society' as 'sokiety' and when corrected they raised the doubt that 'cat' is pronounced as 'kat' and in such case why 'sokiety' is a mistake. Also most of them use 'th' $\left({ }^{\theta}\right)$ sound instead of ' $t$ ' sound. This perhaps might be the impact of their native tongue on their English language acquisition. Even at under graduate level $70 \%$ of them write their examinations of any English course in pencil first and overwrite them in ink. This is something an uncommon gesture to any non-Arabic teacher and at the same time provides clear picture of their cognitive learning standards of target language.

\subsection{Other studies endorsing the limitations}

Congruous to these observations, the studies made by Mukattash [2], Suleiman [3], Zughoul [4], and Ibrahim [5] aptly stated that Arab students' problems in learning English usually spring from the reasons that "school graduates have lack of information regarding the university or college they enrolled in; there is deficiency in the English language curricula offered by some schools and universities; poor teaching methodology; problems with proper language environments; and lack of personal impetus on the part of the students."

\subsection{EFL for girl students in Arab world}

'Necessity is the mother of invention,' as the proverb says without a need no skill is acquired. Either due to religious or cultural aspects, girls in the Arab world are not yet independent to pronounce their needs, especially in academic arena. After graduating and getting employment, English language never stood as a barrier to their career progress within their country. Besides, University instructs the faculty not to go beyond the prescribed text books either in classroom teaching or in conducting examinations.

\section{Research Method}

All the above mentioned observations however help in preparing a teacher to understand and empathize with the students and accordingly program his/her teaching-learning process. The following are the aspects incorporated in my Teaching-learning process to make EFL learning more interesting and enjoying.

\subsection{Rich Felder's effective teaching}

'College teaching may be the only skilled profession for which no preparation or training is provided or required.' [6] Keeping this fact in view Rich Felder, after doing enough of research, came up with well-defined instructional techniques that make teaching more effective. Since it is not possible to incorporate all aspects at one time, emphasis is given on Learning styles, Teaching styles, Bloom's Taxonomy and In-class activities such as minute-paper, think-pair share, cooperative note-taking etc.

\subsection{TESOL}

Representing a highly practical approach to English Language teaching TESOL program catalyses the EFL teachers by acquainting them with Direct method, Self-access method, utilization of drawing skills, warmers, quantification etc.

\subsection{Multimedia}

Science and technology advanced in all aspects of human life enabling us to have a dialogue with the Universe. One should be wise enough to choose an apt one from the myriad products. For EFL teachinglearning process power point presentations with animations are more conducive.

\subsection{ICT resources}

In the present digital word, a traditional teacher is waned away and transformation in the teacher and teaching methods has become inevitable. The integration of information and communication technology (ICT) in the classroom, multiplied the knowledge resources and driven away the monotony in teaching-learning process. 


\subsection{Subjects taught}

\section{Pedagogical implications}

All the above mentioned aspects are incorporated to teach Syntax, Shakespeare, Semantics, and Literary Criticism to students in the University College located in the suburbs of the most traditional Arab country.

\subsection{Learning Styles}

As an active participant in Faculty Learning Institute (FLI 2009) workshop on Effective Teaching by Rich Felder and Rebecca Brent hosted by Indo-US collaboration of Engineering Education in association with Infosys, held at Mysore, India, I received virtual training in the following insightful aspects of teaching-learning process. Learning styles are defined as the preferred ways by which people learn. According to Rich Felder, identifying the learning styles of the students can help structuring the teaching process. Students preferentially take in and process information in different ways by: seeing and hearing, reflecting and acting, reasoning logically and intuitively, analyzing and visualizing, steadily and in fits and starts.

- reflecting and acting - Active and Reflective Learners

- reasoning logically and intuitively - Sensing and Intuitive Learners

- seeing and hearing -Visual and Verbal Learners

- analyzing stepwise and visualizing as a whole - Sequential and Global Learners

- learning from specifics and learning from concepts - Inductive and Deductive Learners

While teaching first semester in traditional chalk and talk method, due attention has been paid to indentify the above learning styles in the students. This helped me design my material, lesson plan, hand outs, assignments and in-class activities.

\subsection{Teaching Styles}

Adapting to the learning styles the following teaching styles suggested by Rich Felder are taken into consideration for effective organization of course work.

- Content - Concrete examples, Simple language, small sentences, examples are drawn from daily activities or experience of the students.

- Presentation - multimedia presentation, with animations, pictures and effects, along with hand outs. Sentences are made more picturesque enabling the students to understand the sentence through picture.

- Organization - Lesson is organized in deductive mode, since most of the average and below average students in the class preferred to learn from the general/theory/concept and then move to specifics or application.

- Participation - The presentation is focused towards activating the passive learners. Think-pair share, cooperative note-taking pairs, writing assignments, minute paper, etc., are tucked in the process effectively so that active learners also feel responsible and get engaged.

- Perspective - The presentation is towards sequential perspective allowing the students to go with step by step understanding.

\subsection{Consequences of Learning and Teaching Style mismatch}

Absenteeism, boredom, apathy, drop outs are the major outcomes of mismatches. Keeping this in view every day presentation is objectively evaluated to check for the mismatches and accordingly suitable changes are incorporated to minimize them. This quantification allowed me to understand the students' approachability, accessibility and adaptability and to choose more suitable pedagogical methods with a tag line: 'I am teaching are they learning?'

\subsection{Blooms Taxonomy}

Educational objectives are set for the lesson plan taking Bloom's cognitive domain into consideration. According to Bloom the lower-order thinking skills are remembering, understanding, applying; and higher-order thinking skills are analyzing, evaluating and creating. This facilitated construction of in-class activities, out-ofclass assignments, and tests. However, major focus is on lower-order thinking skills because of very low English standards of the students. Setting the examinations according to Blooms cognitive domains gave good results in written form and considerable improvement in spoken skills.

Speaking on 'what constitutes exemplary teaching,' Lowman says, "Outstanding teachers have often expressed the sentiment that to become a great classroom instructor, one must genuinely like college-age students and identify with their interests, both serious and foolish."'[7] The three messages given by Lowman are worth remembering to any teacher while structuring the lesson plan. They are: 
- $\quad$ Teaching is about student learning, not disseminating information.

- Your students are not like you.

- $\quad$ You must genuinely like your students, believe they want to learn, and believe that they have the ability to learn.

\subsection{TESOL}

The aspects Felder's 'Effective teaching' helped me reshape my teaching-learning process. After one year, practicing the implementation of the above mentioned aspects, I took TESOL 120 hours in-class training. This acquainted me with Direct method and Self access method and also various class-room activities and warmers. My drawing skills became very effective tool in the instruction process. Introducing warmers, which is totally new to them, gave effective results in sustaining their receiving mood. Most of the average and below average students tend to learn English through transliteration of the content into Arabic. For these students using warmers in the class gave effective result. Warmers designed based on grammar topics promoted kinesthetic learning in them. For instance, write an adjective, give an antonym, add a word and frame a sentence, identify the parts of speech etc. are a few warmers that I used while teaching Syntax and Semantics.

Minute-Paper without any exception catalyzed in recapping the content and gave enough space to clarify the doubts of the students. I implemented 'think-pair share,' dividing the students into teams based on their learning styles. Each team contains all types of learners so that their problem solving skills will be integrated. Despite the fact that the students are not allowed to spend time together outside the college hours, they did their best. I am happy that it gave genesis to academic interaction and sharing among them. Another important aspect is that non-Arabic teachers instructing them, left them with no choice and they slowly got accustomed to speak at least broken English mixing with some Arabic. In toto, there is visible change in students' perspective, yet more years and effort are required to bring desired results in English Language acquisition.

\subsection{Multi-media and ICT resources}

Training, experience and passion towards teaching enabled me to prepare my own power point presentations taking the help of ICT resources to teach Syntax, Semantics, Shakespeare and Literary Criticism. Using ICT tools to teach literature is another big challenge. For orthodox religious mindset it is not easy to perceive the depiction of western life, style and expression in various literary forms either a novel or a drama. Though many classics are available in movie form the teacher cannot use them as it is in the classroom. The teacher needs to be wise enough and keep the limitations in mind while using the resources.

Animations to some extent stood as a better alternative in this regard. To teach Shakespeare's dramas $\mathrm{BBC}$ produced animation movies became more approachable in the given conditions. Also, animation effects augmented simplification and made teaching-learning process more interactive. The outcome is not less commendable. Students slowly if not suddenly could feel less burdened learning English language and Literature. They could write considerably good length of essays instead of mere words and sentences. Most of them prepared themselves to pursue Masters in English Language and Literature. Also, it reduced the discomfort of language barrier, increased the rapport between teacher and the student, helped replacing gossips with discussions on problem solving assignments, and gave way to students' in-class presentations and team work. This change made teaching-learning process more palatable despite many limitations.

Any workshop or training course is meticulously structured to an ideal academic environment. But in reality teaching-learning process might demand more adaptations on the part of the teacher. The best method of teaching comes out of a teacher not just with training but with better understanding of the students and effective utilization of ICT resources and multi-media that permeates apt blending of various pedagogies from traditional approach to modern innovative approaches. In this regard every teacher is highly individualistic and idiosyncratic. And one is absolutely right in one's own way of teaching.

The following resources are used in the class room:

$\mathrm{BBC}$ version animation movies of Hamlet and As You Like It;

http://www.folger.edu/Content/Teach-and-Learn/Teaching-Resources/Study-Guides/Hamlet/

http://www.sparknotes.com/shakespeare/asyoulikeit/context.html

http://www.bardweb.net/study.html

http://www.shakespeare-literature.com/

http://www.playshakespeare.com/news/3722-playshakespeare-com-and-the-shakespeare-society-join-forces

\section{Conclusion}

I designed and practiced what I have leant and experienced great satisfaction. This made me more malleable and enabled to work even in the most traditional Arab country. I never diverged my attention from the words of Benjamin Franklin: "Tell me and I forget. Teach me and I remember. Involve me and I learn."[8] 
Oriented in this direction my teaching-learning process gave enough improvement in students' English language acquisition skills. They could think independently to some extent and able to write their own sentences in English. They started interacting with the teacher in English. They wonderfully able to write essay type answers. This is just a beginning and many more contributions might come in the near future. This paper is my sincere attempt to incubate my experience and to provide a preparatory glance for those who wish to see their career prosperity in the Arab world.

\section{References:}

[1]. I. A. Khan, Learning Difficulties in English: Diagnosis and Pedagogy in Saudi Arabia. Educational Research, 2(7), July 2011. 1248-1257.

[2] L. Mukattash, The Problem of difficulty in foreign language learning, In E. Dahiyat, and M. Ibrahim(eds.), Papers from the First Conference on the Problems of Teaching English Language and Literature at Arab Universities, University of Jordan, AmmanJordan. 1983.

[3] S. Suleiman, Teaching English to Arab students at the university level, In Dihayat and Ibrahim (eds.), Papers from the First Conference on the Problems of Teaching English Language and Literature at Arab Universities, University of Jordan, AmmanJordan. 1983.

[4] M. Zughoul, The unbalanced program of the English department in the Arab world, In Dihayat and Ibrahim (eds.), Papers from the First Conference on the Problems of Teaching English Language and Literature at Arab Universities, University of Jordan, AmmanJordan. 1983.

[5] M. Ibrahim, The Role of English Departments in Arab Universities, In Dihayat and Ibrahim (eds.), Papers from the First Conference on the Problems of Teaching English Language and Literature at Arab Universities, University of Jordan, Amman-Jordan. 1983.

[6] R. M. Felder, \& R. Brent, Understanding Student Differences. Journal of Engineering Education, 94(1), 2005. 57-72.

[7] Teaching Techniques, Retrieved from https://www.google.co.in/\#q=what+constitutes+exemplary+teaching\%2C\%E2\%80\%99+Lowman+says\%2C+

[8] Teacher quotes, Retrieved from http://adultesljobs.com/teacher-quotes/ 